Available online on 15.05.2018 at http://jddtonline.info
Journal of Drug Delivery and Therapeutics
Open Access to Pharmaceutical and Medical Research
$\begin{gathered}\text { (2011-18, publisher and licensee JDDT, This is an Open Access article which permits unrestricted non- } \\ \text { commercial use, provided the original work is properly cited }\end{gathered}$

Open $\odot$ Access

Research Article

\title{
COMBINED USE OF DSC, TGA, XDR AND NIR IN THE COMPATIBILITY STUDY OF PREFORMULATION MIXTURES FOR THE DEVELOPMENT OF 10 MG TABLETS OF RUPATADINE FUMARATE
}

\author{
Luis Castillo Henríquez $^{1 *}$, German Madrigal Redondo ${ }^{2}$, Rolando Vargas Zúñiga ${ }^{3}$, Gustavo Carazo Berrocal ${ }^{4}$ \\ ${ }^{1}$ Doctor in Pharmacy, Professor and Researcher of the Biopharmacy and Pharmacokinetics Laboratory (LABIOFAR) of the Institute \\ of Pharmaceutical Research (INIFAR), and the Pharmaceutical Physicochemistry Laboratory of the University of Costa Rica \\ Pharmacy Faculty, Rodrigo Facio Campus, San Jose, Costa Rica, Postal Code 11501-2060, San José, Costa Rica. \\ 2 \\ 2 Doctor in Pharmacy, Magister in Intellectual Property, Magister Scientae in Analysis and Quality Control of Medications, \\ Associate Professor and Researcher of the Biopharmacy and Pharmacokinetics Laboratory (LABIOFAR) of the Institute of \\ Pharmaceutical Research (INIFAR), and the Pharmaceutical Physicochemistry Laboratory of the University of Costa Rica Pharmacy \\ Faculty, Rodrigo Facio Campus, San Jose, Costa Rica, Postal Code 11501-2060, San José, Costa Rica. \\ 3 Doctor in Pharmacy, Master in Intellectual Property, Professor and Researcher of the Biopharmacy and Pharmacokinetics \\ Laboratory (LABIOFAR) of the Institute of Pharmaceutical Research (INIFAR), and the Pharmaceutical Laboratory of the \\ University of Costa Rica Pharmacy Faculty, Rodrigo Facio Campus, San José, Costa Rica, Postal Code 11501-2060, San José, Costa \\ Rica. \\ ${ }^{4}$ Doctor in Pharmacy, Magister Scientae in Analysis and Quality Control of Medications, Professor and Researcher of the \\ Biopharmacy and Pharmacokinetics Laboratory (LABIOFAR) of the Institute of Pharmaceutical Research (INIFAR), and the \\ Pharmaceutical Physicochemistry Laboratory of the University of Costa Rica Pharmacy Faculty, Rodrigo Facio Campus, San Jose, \\ Costa Rica, Postal Code 11501-2060, San José, Costa Rica.
}

\section{ABSTRACT}

It is essential to guarantee physico-chemical compatibility between the active pharmaceutical ingredient (API) and the components that are planned to be used in the development of a pharmaceutical formulation. A successful compatibility study allows distinguishing between the excipients that can be used and those that may represent a risk in the quality, safety and efficacy of the medication. The present study focuses on the identification of possible incompatibilities between Rupatadine fumarate and the excipients of three formulation prototypes for the development of API's $10 \mathrm{mg}$ tablets. Samples of each raw material, placebos and preformulation mixtures were analyzed by differential scanning calorimetry (DSC), thermogravimetric analysis (TGA), X-ray diffraction (XDR) and infrared spectroscopy (IRS). The results obtained were analyzed and contrasted with the literature. Based on these, it is demonstrated that the excipients used along with the API do not generate problems in terms of compatibility, as there are no chemical changes in the drug.

Key words: Active pharmaceutical ingredient, Chemical incompatibility, Compatibility study, Differential scanning calorimetry, Infrared spectroscopy, Preformulation powder mixtures, Rupatadine fumarate, Thermal analysis, Thermogravimetric analysis, X ray diffraction.

Article Info: Received 18 Feb, 2018; Review Completed 14 April 2018; Accepted 16 April 2018; Available online 15 May 2018

Cite this article as:

Luis $\mathrm{CH}$, German MR, RolandoVZ, Gustavo CB, Combined use of DSC, TGA, XDR and NIR in the compatibility study of preformulation mixtures for the development of $10 \mathrm{mg}$ tablets of rupatadine fumarate, Journal of Drug Delivery and Therapeutics. 2018; 8(3):42-54 DOI: http://dx.doi.org/10.22270/jddt.v8i3.1727

\section{*Address for Correspondence:}

Luis Castillo Henríquez, Doctor in Pharmacy, Professor and Researcher of the Biopharmacy and Pharmacokinetics Laboratory (LABIOFAR) of the Institute of Pharmaceutical Research (INIFAR), and the Pharmaceutical Physicochemistry Laboratory of the University of Costa Rica Pharmacy Faculty, Rodrigo Facio Campus, San Jose, Costa Rica, Postal Code 11501-2060, San José, Costa Rica. 


\section{INTRODUCTION}

It is mandatory to investigate the different fundamental physical and chemical properties of a drug, as well as the excipients that are planned to be used in the design of a product. This initial phase is known as "preformulation", and base on its findings it is intended to design a pharmaceutical form that guarantees quality, safety and efficiency from early stages, by anticipating possible problems that may arise during the formulation process and that may lead to a risk in the stability of the medication. ${ }^{1}$

Compatibility studies within the pharmaceutical preformulation process consist in the evaluation of the drug in the presence of those excipients that are expected to be incorporated in the pharmaceutical form. Therefore, it is intended to detect in a relatively short period of time, possible physicochemical interactions or incompatibilities between the excipients and the active pharmaceutical ingredient (API), in order to avoid the formation of degradation products in the pharmaceutical form. ${ }^{2,3}$

Stability prediction methods under accelerated conditions, like isothermal stress through a stability chamber, require long periods of time and also specific methods of analysis for both, the API and the degradation products. Given the above, there are other methods for the conduction of solid compatibility studies that are available for the researcher, such as the thermal analysis. ${ }^{4,5,6}$

Differential Scanning Calorimetry (DSC) and Thermogravimetry (TGA) are techniques that allow the thermal characterization of the raw materials of interest, as well as a quick and preliminary identification of possible interactions or physicochemical incompatibilities that occur between the API and the excipients. ${ }^{6,7}$

To carry out a compatibility study, it is necessary to prepare mixtures of the components that are subject of the study. The formulator is able to analyze binary mixtures or the matrix, in order to determine interactions between the components of interest that can result in a physical and/or chemical change. The way in which these physical mixtures are prepared will depend on the scope wished for the study. In many cases, mixtures in a 1:1 ratio may represent an enormous stress for the components which is not going to be reached according to the design established during the formulation stage. Therefore, for drug development, several authors support the utility of evaluating the compatibility between the components of a formulation, through the preparation of mixtures that contain all of them in the real proportion in which they will be found in the pharmaceutical form. ${ }^{\mathbf{8 , 9}}$

The API involved in the present compatibility study is Rupatadine fumarate (see figure 1), its IUPAC nomenclature is 8-chloro-6, 11-dihydro-11- [1- [(5methyl-3-pyridyl) methyl] -piperidin-4-ylidene] $-5 \mathrm{H}$ benzo $[5,6]$ cyclohepta $[1,2-b]$ pyridine fumarate. The compound constitutes a potent selective second generation antihistamine of the $\mathrm{H} 1$ receptor, reason why it is widely used in the symptomatic treatment of allergic rhinitis and urticaria in adults and children older than 12 years, with a daily dose of $10 \mathrm{mg}$. ${ }^{\mathbf{1 0}, \mathbf{1 1}, \mathbf{1 2}, 13}$<smiles>Cc1cncc(CN2CCC(=C3c4ccc(Cl)cc4CCc4cccnc43)CC2)c1</smiles><smiles>O=C(O)C=CC(=O)O</smiles>

Figure 1: Chemical structure of Rupatadine fumarate.

For the execution of the present compatibility study, the analysis of placebo samples and mixtures that include the API will be done through techniques such as DSC, TGA, Infrared spectroscopy (NIR) and X ray diffraction (XDR). The results of the preformulation mixtures and placebos will be compared between them and with the analysis made to raw material individually, in order to determine if there are any modifications that cause an alteration of the physicochemical stability of the mentioned mixtures under study.

\section{MATERIALS AND METHODS}

Raw materials used for the research were provided by a national industry. For the execution of this study it was decided to evaluate the compatibility between excipients and active pharmaceutical principle, according to the three formulation prototypes that are shown in the table 2 , where a check means that the component is present and $\mathrm{X}$ means that it is not included

Table 1: Materials used for the research

\begin{tabular}{|l|l|}
\hline Raw materia & Manufacturer \\
\hline Rupatadine fumarate & Enaltec laboratories India, batch No. EL-03/L095/16025. \\
\hline Monohydrate lactose (Supertab® 11SD) & DFE Pharma, batch No. 1010KX2. \\
\hline Microcrystalline cellulose (Pharmacel® 102) & DFE Pharma, batch No. 100202. \\
\hline Sodium croscarmellose & JRS Pharma, batch No. 7111512407. \\
\hline Pregelatinized starch (Superstarch® 200) & DFE Pharma, batch No. 10069PO. \\
\hline Magnesium stearate & Helianthus, batch No. MGSV150475. \\
\hline Stearic acid & BTP Pharma, batch No. 20150620. \\
\hline PVP K-30 & Ashland, batch No. 0001855552 \\
\hline
\end{tabular}


Table 2: Qualitative composition of the preformulation mixtures

\begin{tabular}{|c|c|c|c|}
\hline Raw materia & Formula $1(\%)$ & Formula $2(\%)$ & Formula $3(\%)$ \\
\hline Rupatadine fumarate & $\boldsymbol{v}$ & $\checkmark$ & $\boldsymbol{V}$ \\
\hline Monohydrate lactose & $\checkmark$ & $\checkmark$ & $\checkmark$ \\
\hline Microcrystalline cellulose & $v$ & $\checkmark$ & $\checkmark$ \\
\hline Sodium croscarmellose & $V$ & $\checkmark$ & $\mathrm{X}$ \\
\hline Pregelatinized starch & $\mathrm{X}$ & $\mathrm{X}$ & $\checkmark$ \\
\hline Magnesium stearate & $\checkmark$ & $\checkmark$ & $\mathrm{X}$ \\
\hline Stearic acid & $\mathrm{X}$ & $\mathrm{X}$ & $\checkmark$ \\
\hline PVP K-30 & $\mathrm{X}$ & $\checkmark$ & $\mathrm{X}$ \\
\hline
\end{tabular}

Initially, raw materials were sieved using a mesh 20 . After that, both, placebo mixtures and the ones with the API were prepared in the real proportion according the prototype. Five grams samples of each powder mixture were taken randomly and transferred to the test site under controlled conditions of temperature, light and humidity. The conditions and specifications of the equipments used are:

\section{Differential Scanning Calorimetry}

\section{Equipment}

- DSC TA Instruments model Q200.

\section{Conditions}

- Aluminum capsule.

- $100 \%$ Nitrogen Atmosphere 10 psi.

- Flowrate: $40 \mathrm{~mL} /$ minute.

- Heating series: isotherm at $20^{\circ} \mathrm{C}$ for 5 minutes, then increase $10^{\circ} \mathrm{C} /$ minute.

- Temperature range: $20^{\circ} \mathrm{C}$ to $250^{\circ} \mathrm{C}$.

- Sensitivity Instrument and Recorder: Sensitivity 0.1 $\mathrm{uW}$.

- Temperature precision: $\pm 0.05{ }^{\circ} \mathrm{C}$.

- Temperature accuracy: $\pm 1{ }^{\circ} \mathrm{C}$.

- Calorimetric precision: $\pm 0.1 \%$.

- Calorimetric reproducibility: $\pm 0.1 \%$.

- Weight: 4 to $5 \mathrm{mg}$ sample.

- Calibration with Indium and distilled water.

- Three replicas.

\section{Thermogravimetric Analysis}

\section{Equipment}

- TGA TA Instruments model Q500.

\section{Conditions}

- $100 \%$ Nitrogen 10 psi Atmosphere.

- Volume flow: $40 \mathrm{~mL} /$ minute.

- Heating rate: $10^{\circ} \mathrm{C} /$ minute.

- Temperature range: $20{ }^{\circ} \mathrm{C}$ to $1000{ }^{\circ} \mathrm{C}$.

- Weight: 4 to $5 \mathrm{mg}$ sample.

- Sensitivity: $0.1 \mathrm{ug}$.

- Isothermal temperatura accuracy: $\pm 0.1 \%$.

- Isothermal temperature precision $\pm 0.1 \%$.

- Three replicas.

\section{Infrared Spectroscopy}

\section{Equipment}

- FTIR Thermo Scientific Nicolet model 6700.

\section{Conditions}

- Range: 600 to $4000 \mathrm{~cm}^{-1}$.

- Temperature: $25^{\circ} \mathrm{C}$.

- Relative humidity: $30 \%$.

- 200 scans per replica.

- Three replicas.

\section{$\mathrm{X}$ ray Diffraction}

\section{Equipment}

- Diffractometer: PANalytical Empyrean.

\section{Conditions}

- Temperature: room temperatura $25^{\circ} \mathrm{C}$.

- Nickel filter.

- Copper anode source $\operatorname{K\alpha }\left(\lambda 1,54 \mathrm{~A}^{\circ}\right)$.

- Polymethacrylate sample holder.

- Continuous analysis at $0.1^{\circ}$ per second in the range of $3^{\circ}$ to $40^{\circ} 2 \theta$.

- Gas detector with photodiodes.

- Weight: 10 to $15 \mathrm{mg}$ sample.

- Three replicas.

\section{RESULTS}

The current investigation studies chemical compatibility between de API, Rupatadine fumarate, and the excipients used in three preformulation mixtures, by making a comparison between the results obtained through different tests applied to the samples, and physicochemical parameters reported on literature and patents. Those results were used to make conclusions about the compatibility of the API with the excipients that can be used in an eventual successful formulation.

\section{Differential Scanning Calorimetry}

Figure 2 shows the results of the thermal analysis made to the samples of Rupatadine fumarate raw material, through DSC. The thermogram presented shows an endothermic event at $201.28{ }^{\circ} \mathrm{C}$ which corresponds to the melting point of the substance. Likewise, a decomposition of the sample is visible after the melting, and it is shown as a transition to an exothermic event around $208{ }^{\circ} \mathrm{C}$. The mentioned melting and decomposition occurs in a narrow range of temperature. There are no other thermal events related with any other decomposition, surface water loss or impurities before the melting point. 


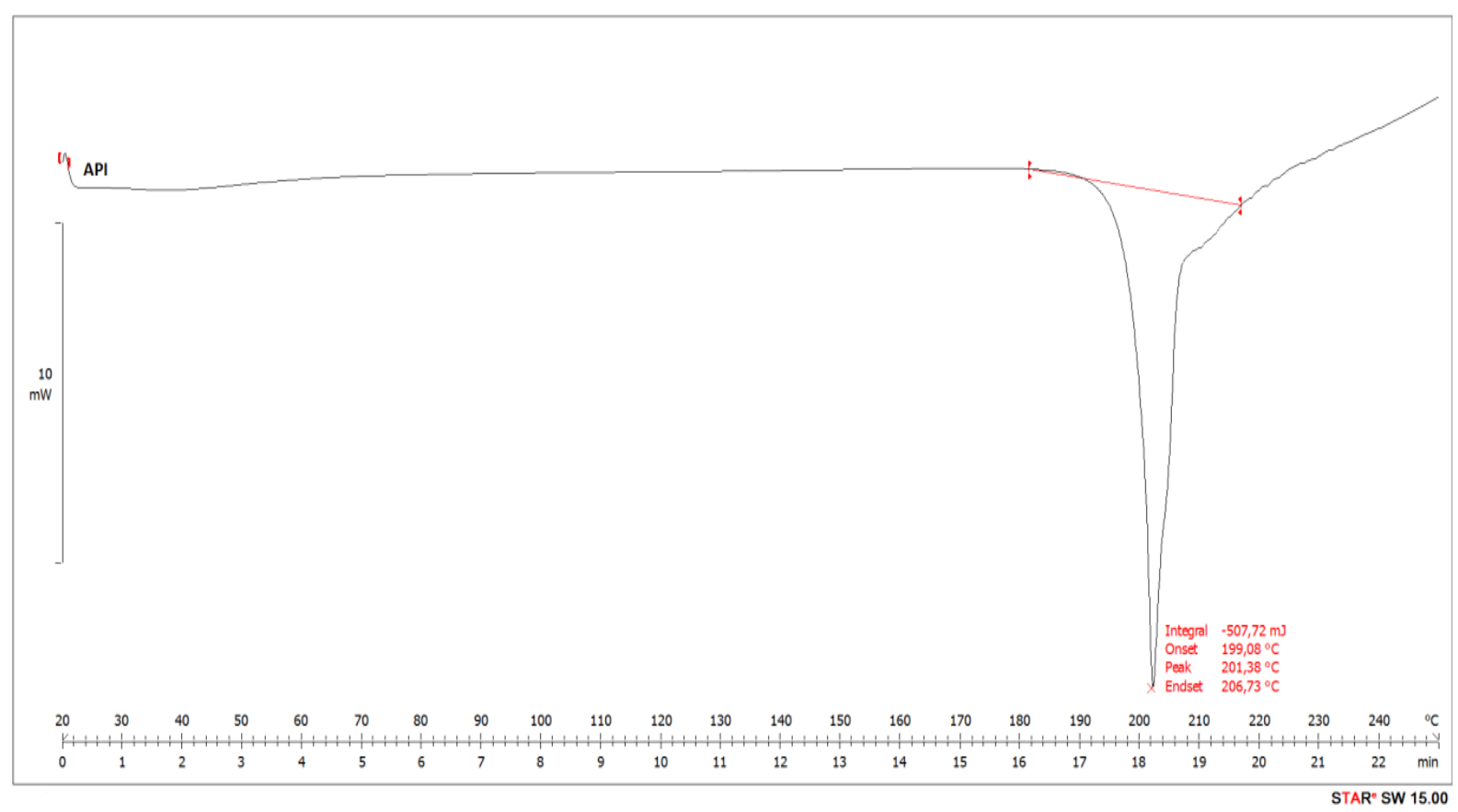

Figure 2: Thermal analysis of Rupatadine fumarate through DSC

Figure 3 shows the results of the thermal analysis made to the excipients used for the samples of the placebos and formulas, through DSC. Based on the thermogram, it is possible to see the following melting points: Monohydrate lactose $218.21{ }^{\circ} \mathrm{C}$, croscarmellose 87.63
${ }^{\circ} \mathrm{C}$, magnesium stearate $80.48{ }^{\circ} \mathrm{C}$ and $115.83{ }^{\circ} \mathrm{C}$, microcrystalline cellulose $72.44{ }^{\circ} \mathrm{C}$, pregelatinized starch $78.35{ }^{\circ} \mathrm{C}$, stearic acid $58.15{ }^{\circ} \mathrm{C}$ and povidone $88.88^{\circ} \mathrm{C}$.

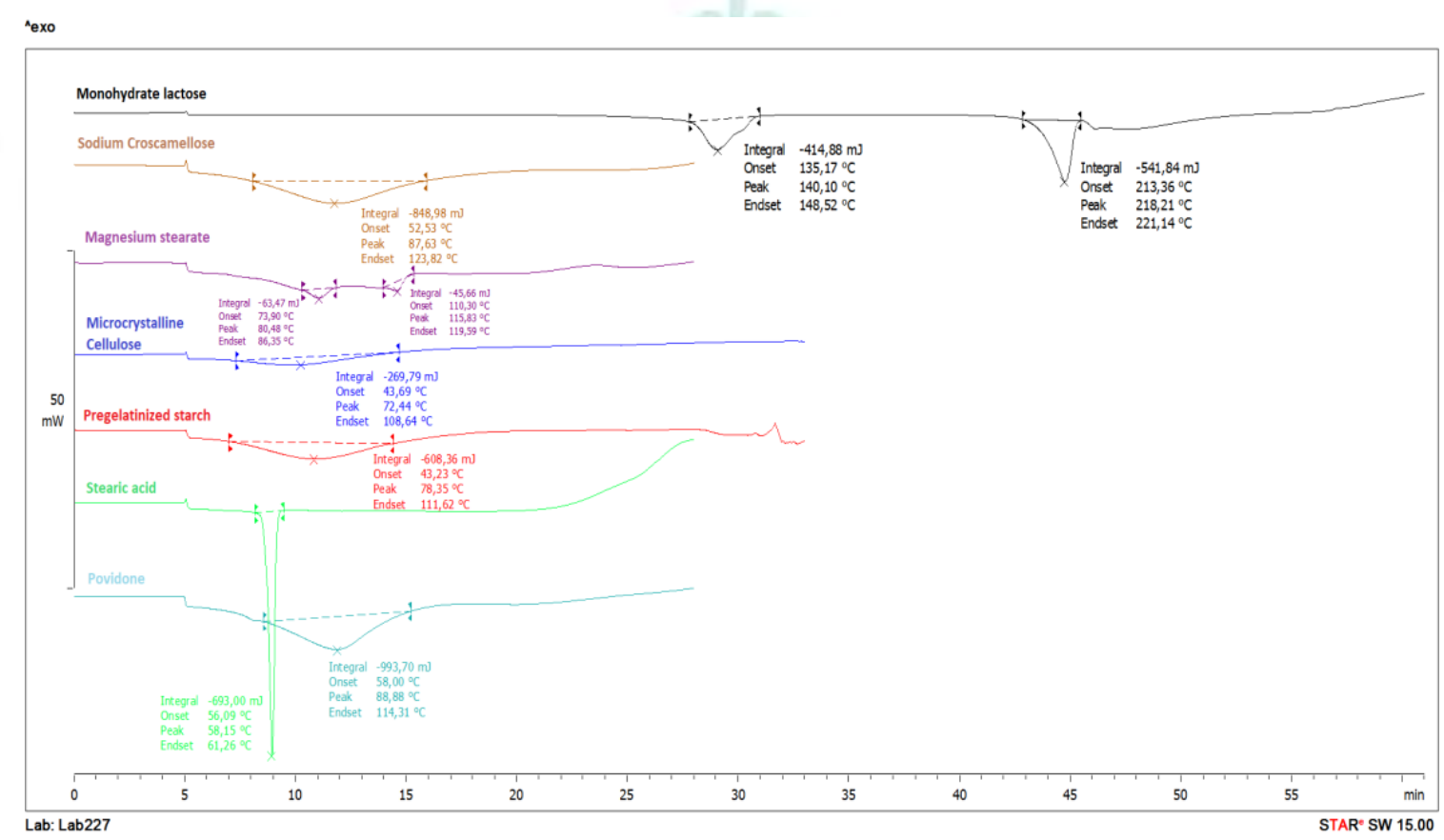

Figure 3: Thermal analysis of the excipients through DSC

Figures 4 - 6 show a comparison of the DSC analysis between the API, placebo and its corresponding formula. According to this methodology, it is possible to notice that every thermogram shows similarities in the placebo and formula behavior, but the most important thing is that there are no new exothermic peaks and the temperature at which the melting of the API occurs in the formula is pretty close to the one of the substance alone. Also, it can be seen that most of the melting or endothermic peaks of the excipients are missing. 


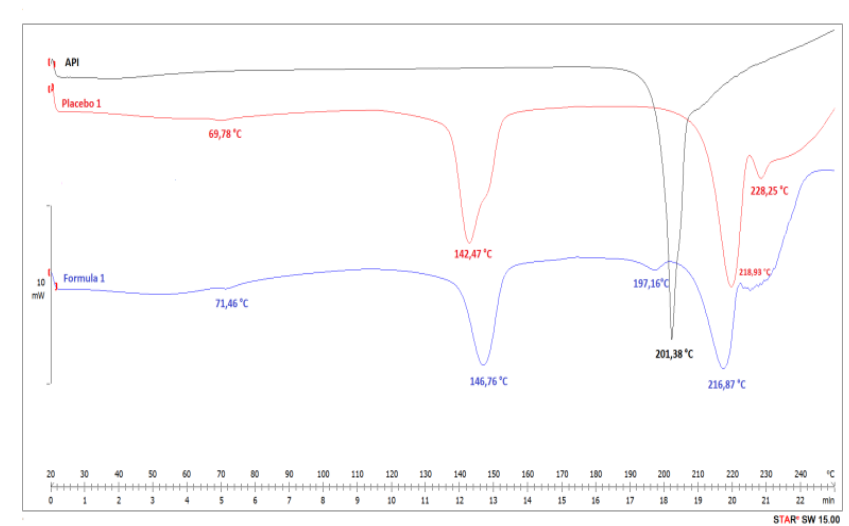

Figure 4: Comparison of the thermal analysis between API, placebo 1 and formula 1 through DSC

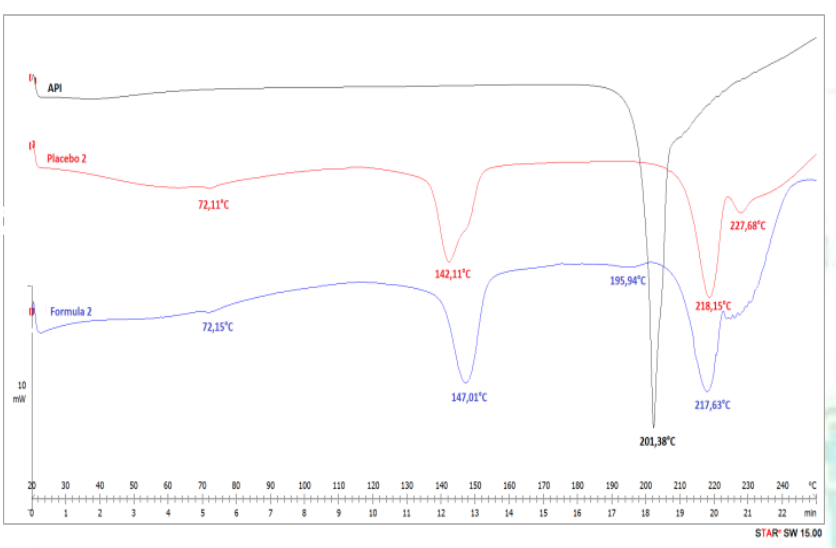

Figure 5: Comparison of the thermal analysis between API, placebo 2 and formula 2 through DSC

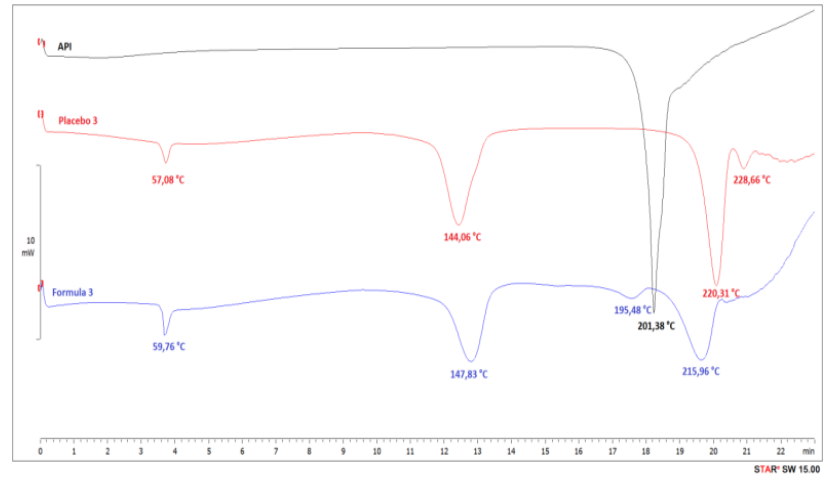

Figure 6: Comparison of the thermal analysis between API, placebo 3 and formula 3 through DSC

\section{Thermogravimetric Analysis}

In order to analyze the results, the thermograms shown were divided in three stages: 1) $0-150{ }^{\circ} \mathrm{C}$, 2) 150 - 400 ${ }^{\circ} \mathrm{C}$ and 3) $400-1000{ }^{\circ} \mathrm{C}$. However, thermal events that take place above $300{ }^{\circ} \mathrm{C}$ are not considered relevant for this analysis.

Figure 7 shows the thermogravimetric analysis of Rupatadine fumarate raw material from Enaltec Laboratories. It can be seen that there's no mass decrease in the first stage. The analysis of the second stage showed about $20 \%$ of mass decrease between 205 ${ }^{\circ} \mathrm{C}-208{ }^{\circ} \mathrm{C}$ and $75 \%$ around $300{ }^{\circ} \mathrm{C}$. It is relevant to say that the test allowed to evaluate and prove sample's purity, as there were any decomposition events or mass losses linked with residual solvents or related substances, present in raw material.

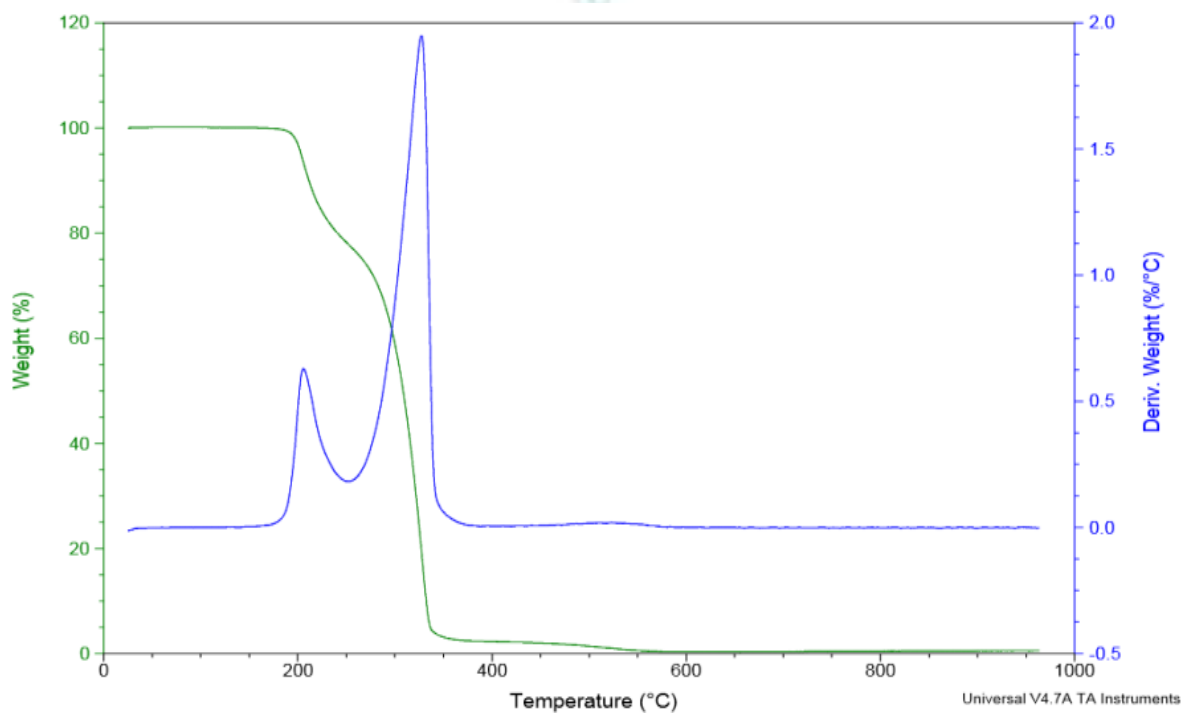

Figure 7: TGA of Rupatadine Fumarate

Figures 8 - 10 show a comparison of the thermogravimetric analysis between the API, placebo and its corresponding formula. Based on the mentioned methodology, the thermograms reveal a similar behavior below $300{ }^{\circ} \mathrm{C}$ between the placebo and its formula. The thermograms show a mass loss at a temperature below $210{ }^{\circ} \mathrm{C}$. Also, they exhibit another mass loss between $280-300{ }^{\circ} \mathrm{C}$, and that event is in agreement with the
API's individual thermogravimetric analysis. In the second stage, the mass loss in the placebos and its corresponding powder formula for prototypes 1 and 2 , constitutes between $67-68 \%$ of the sample. On the other hand, regards to prototype 3 , it is possible to interpret from the thermogram represented in figure 10 , a mass loss of $73 \%$ for the placebo and $71 \%$ for the formula. 


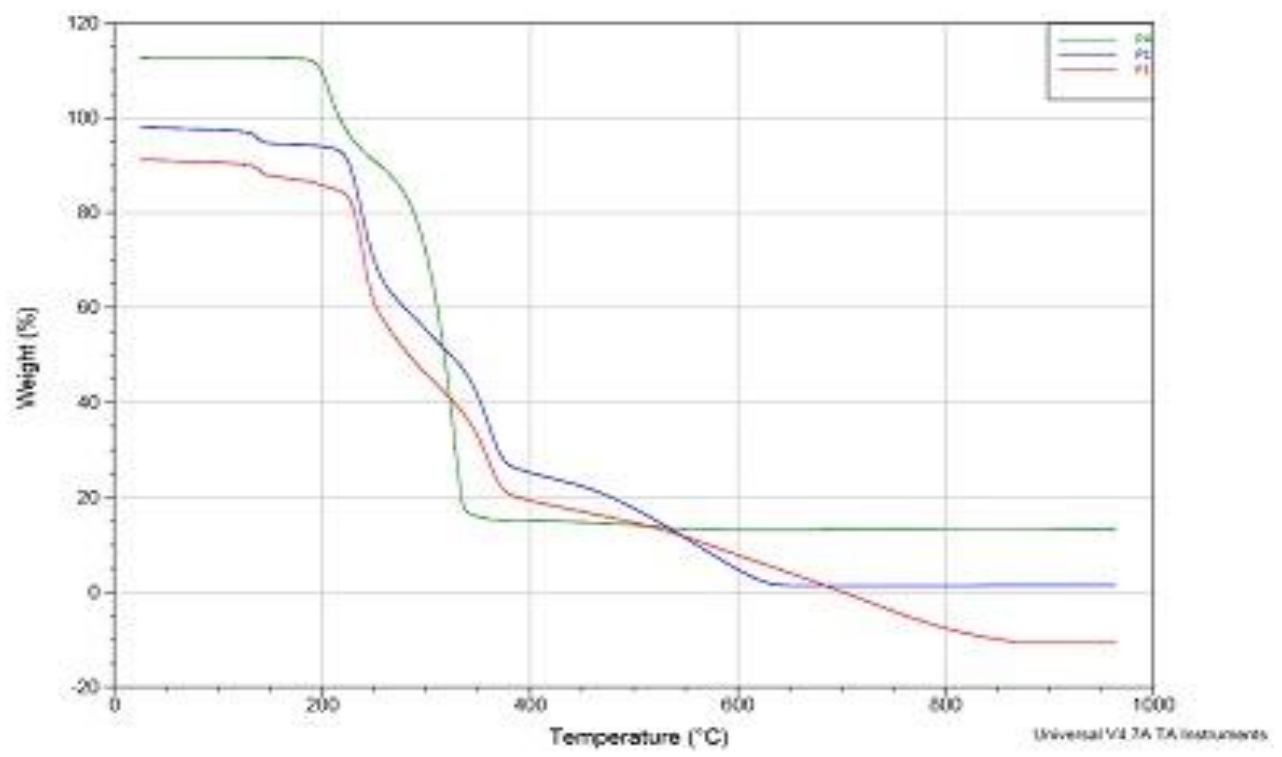

Figure 8: Comparison of the thermal analysis between API, placebo 1 and formula 1 through TGA

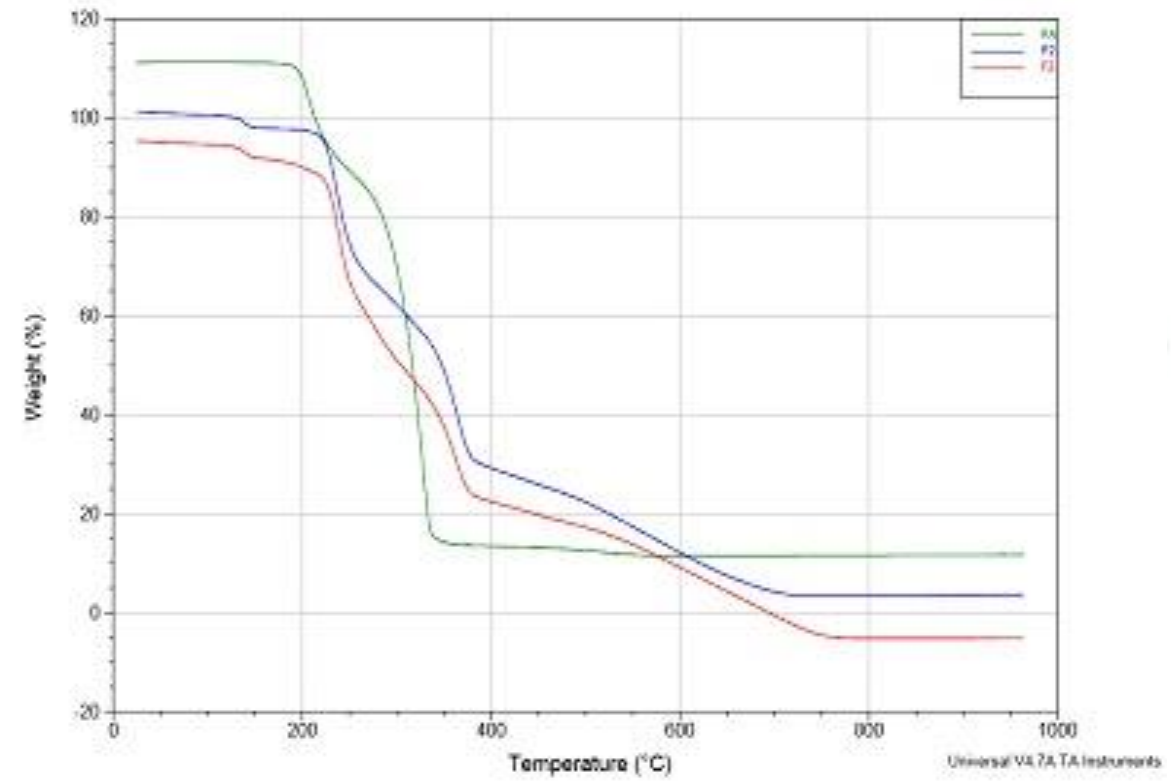

Figure 9: Comparison of the thermal analysis between API, placebo 2 and formula 2 through TGA

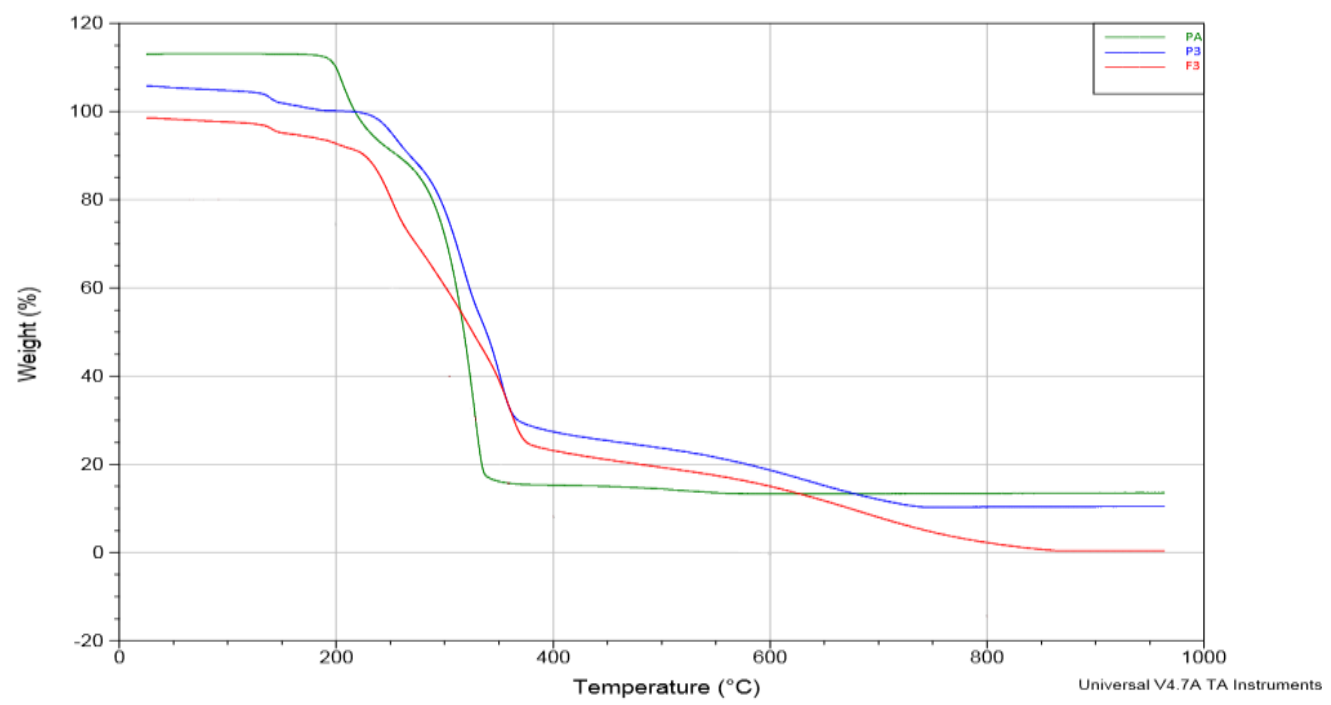

Figure 10: Comparison of the thermal analysis between API, placebo 3 and formula 3 through TGA 


\section{Infrared Spectroscopy}

According to the API's infrared spectrum presented in figure 11 , it is possible to identify the characteristic bands of this molecule in the infrared spectrums of the three formulas, as it can be seen in figures $12-14$. The identification and interpretation of each characteristic band is presented in table 3 .

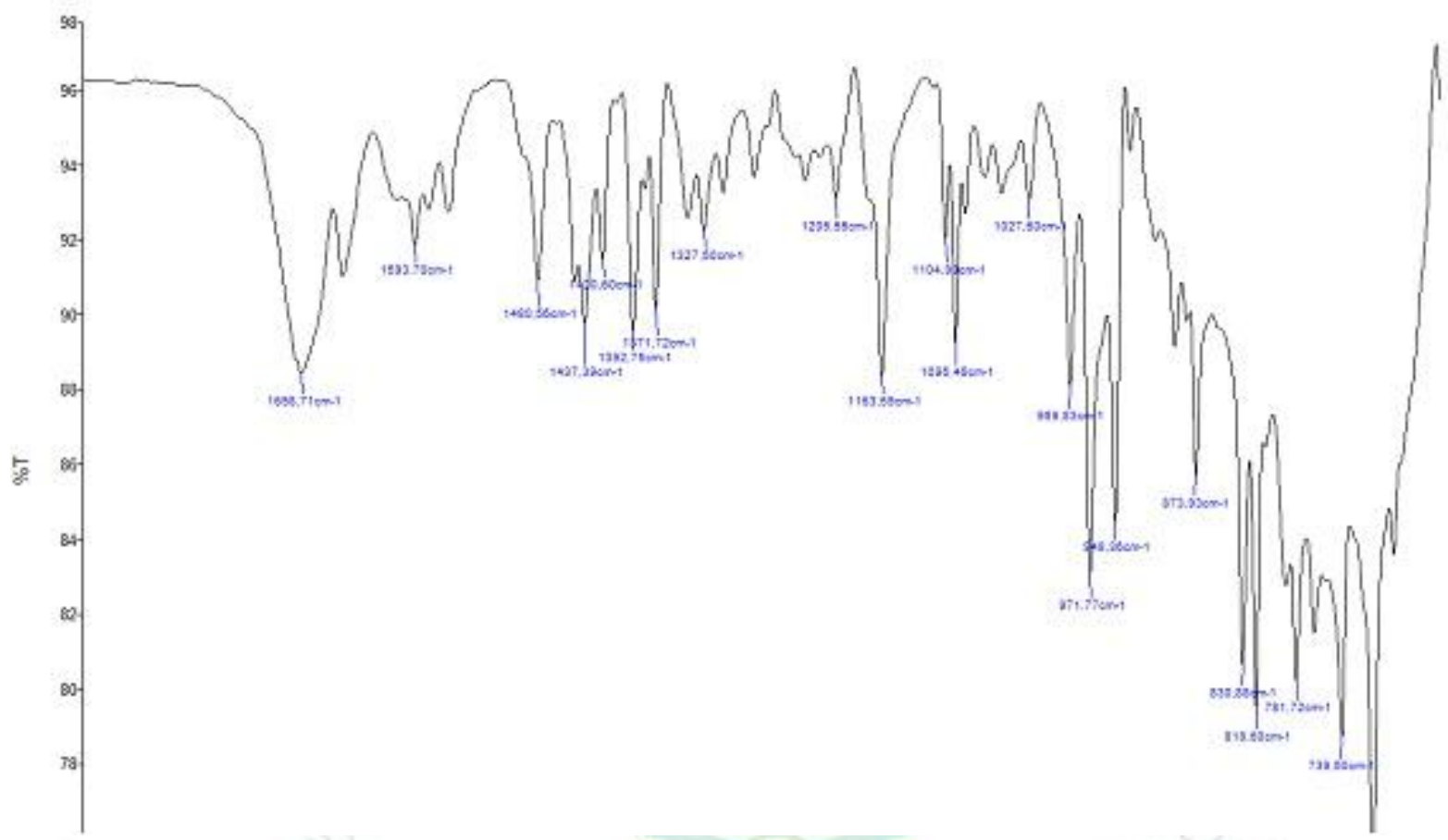

Figure 11: Infrarred spectroscopic analysis of Rupatadine Fumarate

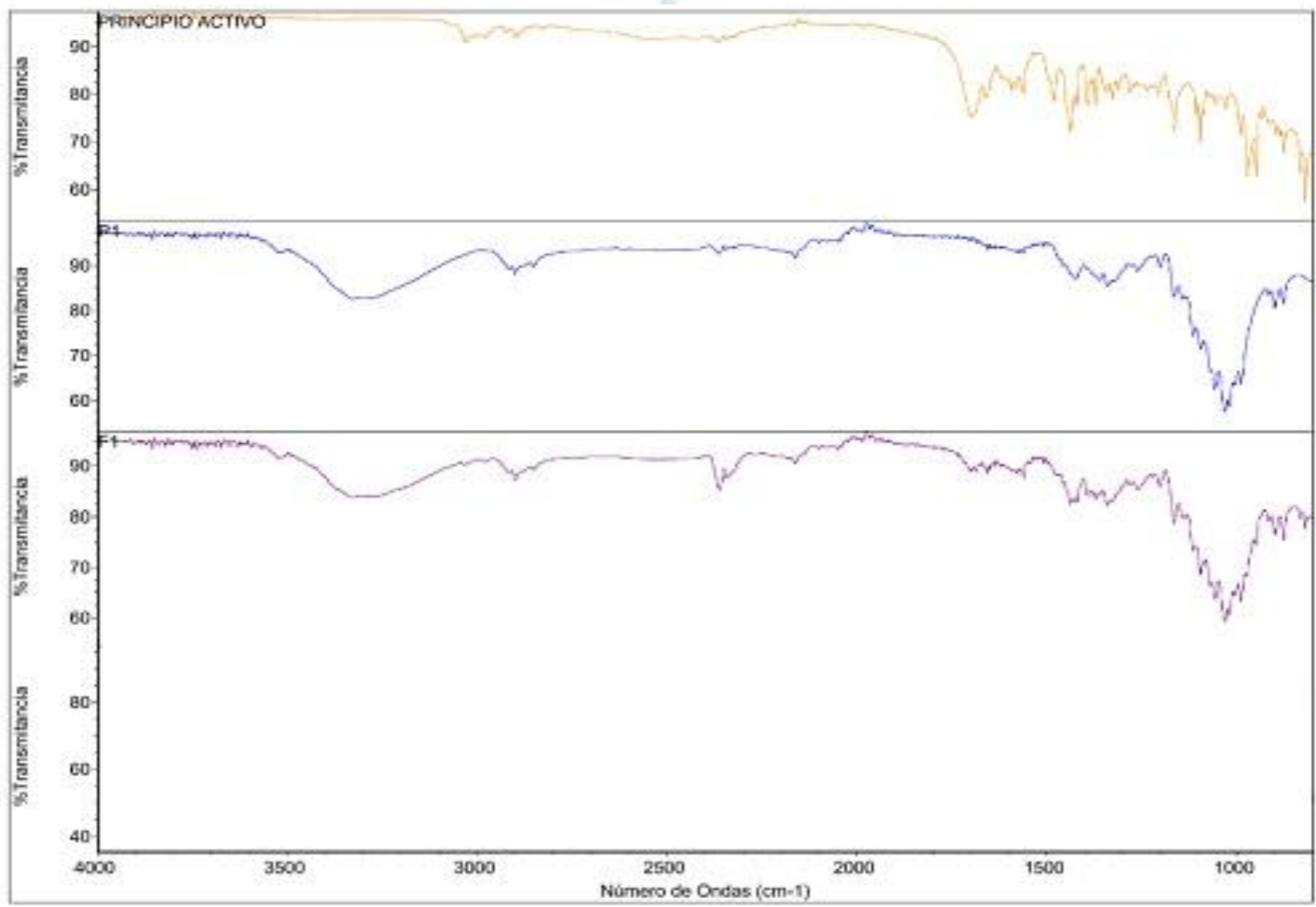

Figure 12: Comparison of the infrared spectroscopic analysis between API, placebo 1 and formula 1 


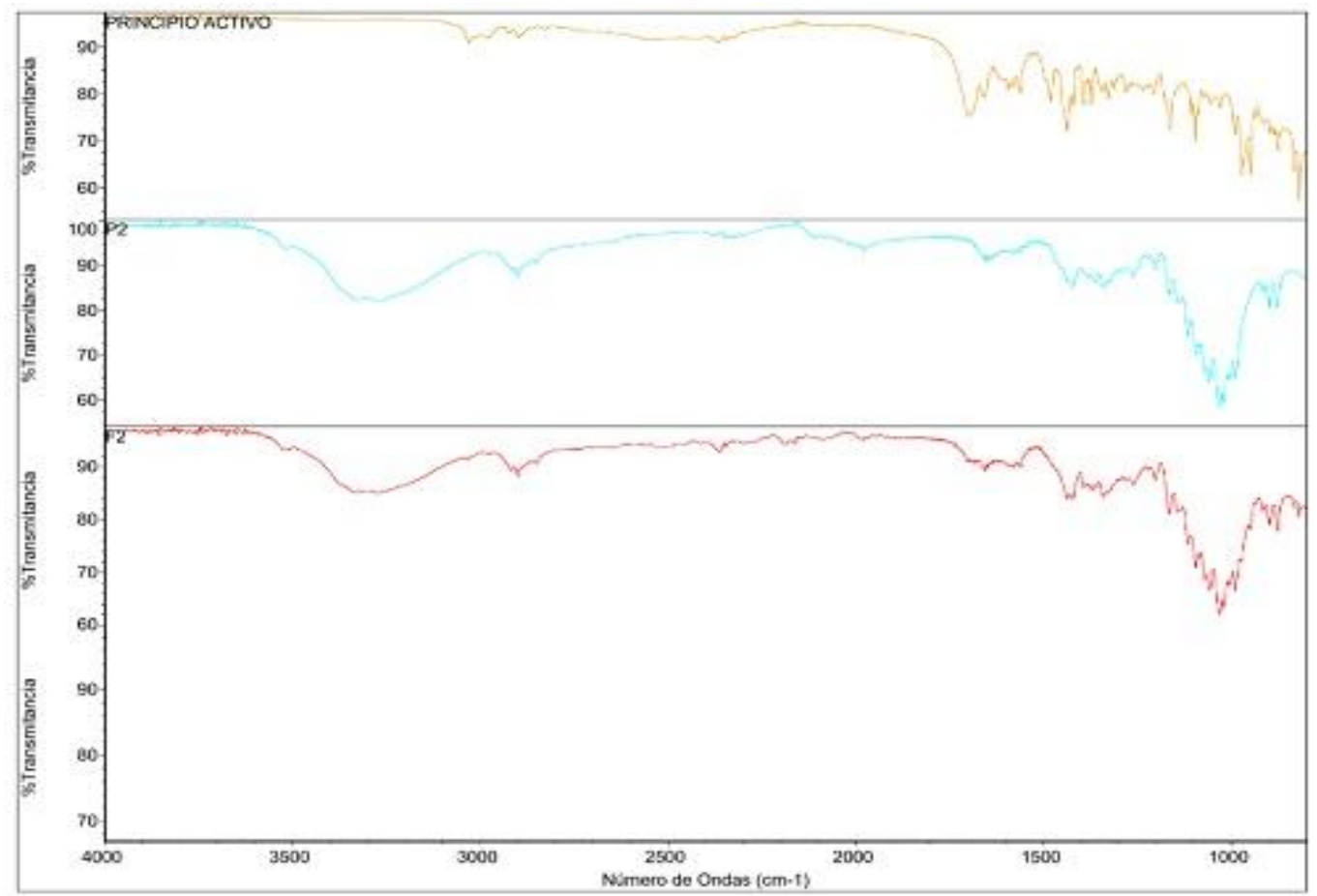

Figure 13: Comparison of the infrared spectroscopic analysis between API, placebo 2 and formula 2

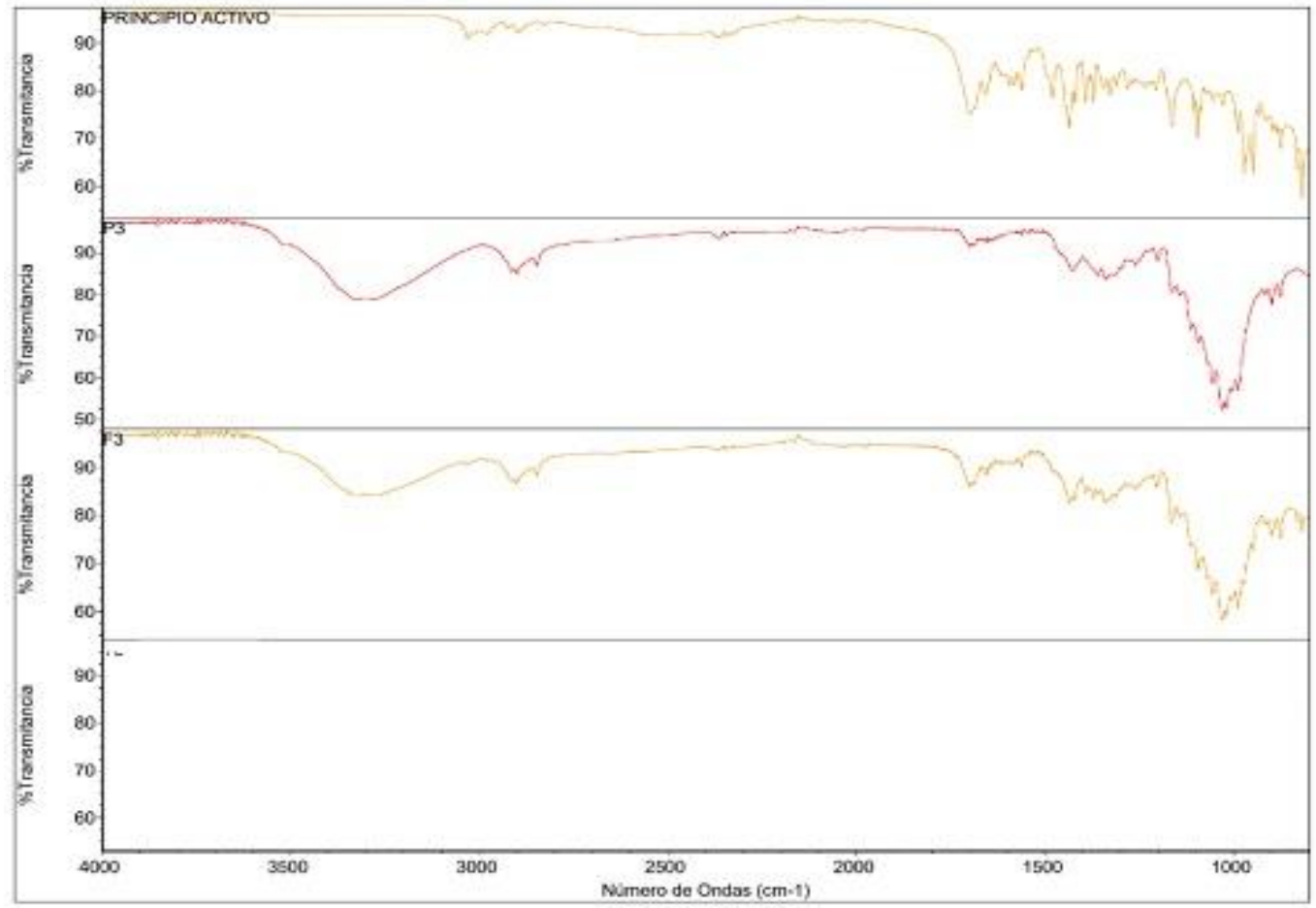

Figure 14: Comparison of the infrared spectroscopic analysis between API, placebo 3 and formula 3

Table 3. IR bands interpretation.

\begin{tabular}{|c|c|c|c|}
\hline $\begin{array}{c}\text { Wave number } \\
\left(\mathbf{c m}^{\mathbf{- 1}}\right)\end{array}$ & Interpretation & $\begin{array}{c}\text { Wave number } \\
\left(\mathbf{c m}^{\mathbf{- 1}}\right)\end{array}$ & Interpretation \\
\hline 2987,41 & C-H stretching of alkanes and aromatic rings. & 1420,6 & O-H splitting of carboxylic acids. \\
\hline 1698,71 & C=O stretching. & 1327,5 & C-N stretching of aromatic amine. \\
\hline 1593,7 & $\begin{array}{c}\text { N-H splitting of an amino group and C=C } \\
\text { stretching of an alkene cycle. }\end{array}$ & $\begin{array}{c}1205,55 \\
\text { group. }\end{array}$ \\
\hline 1437,39 & C-H splitting of an alkane (methyl) group. & $\begin{array}{c}830,88 \text { and } \\
781,72\end{array}$ & C-Cl stretching and vibration. \\
\hline
\end{tabular}




\section{Ray Diffraction}

Figure 15 shows the results obtained through the analysis of the Rupatadine fumarate samples with $\mathrm{X}$ ray diffraction. The mentioned figure represents a classic pattern of a crystalline substance. In a previous investigation, we confirmed that this molecule hasn't any other polymorphic forms besides A form, same as it is established in the literature. ${ }^{\mathbf{1 4}, 15}$

This crystalline form exhibits two principal peaks, the first one around $202 \theta$ and the second one is near $252 \theta$.
Even though, there are four other peaks of lower intensity around 13,17, 21 and $232 \theta$, they are still relevant for the characterization and identification of the crystalline form. The placebos samples show characteristic peaks of each crystalline component included. It is important to highlight that the diffractogram of each formula shows both, the peaks of the API, as well as the excipients contained in the corresponding placebo, as it can be seen in figures 16 18.

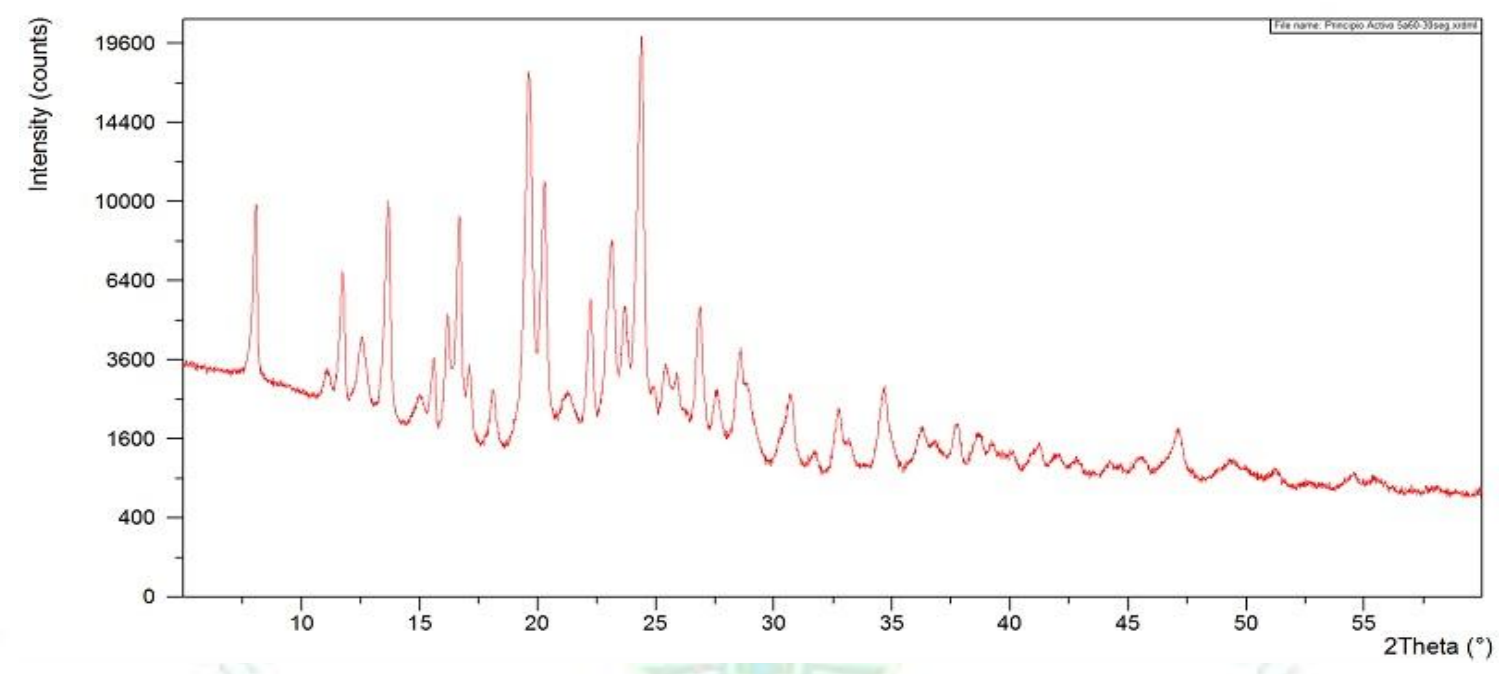

Figure 15: X-ray diffractometry of Rupatadine fumarate

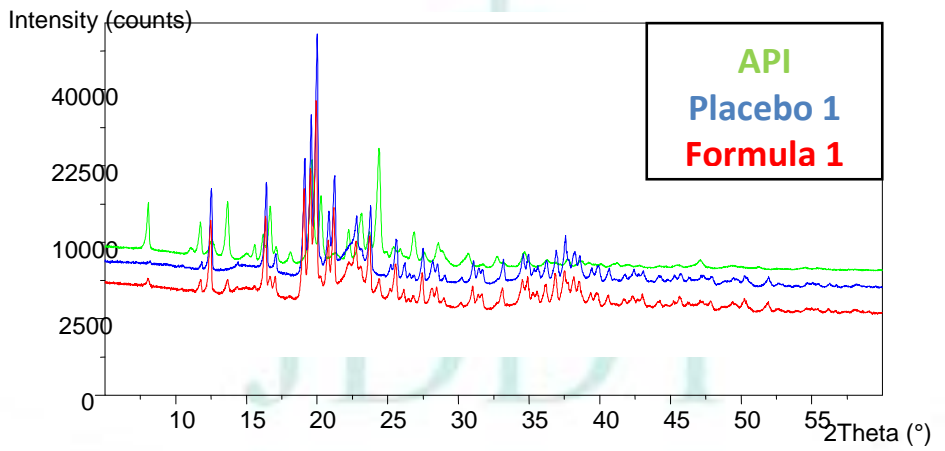

Figure 16: X-ray diffractometry comparison between API, placebo 1 and formula 1

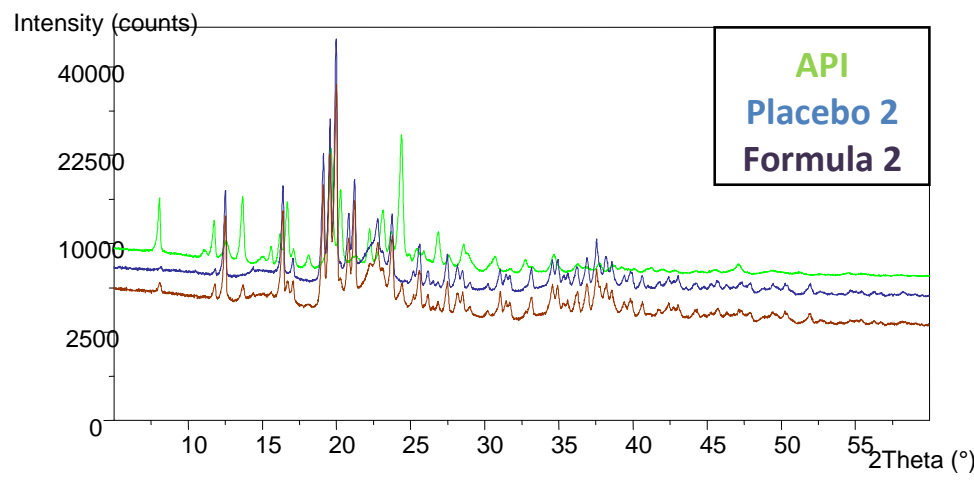

Figure 17: X-ray diffractometry comparison between API, placebo 2 and formula 2 


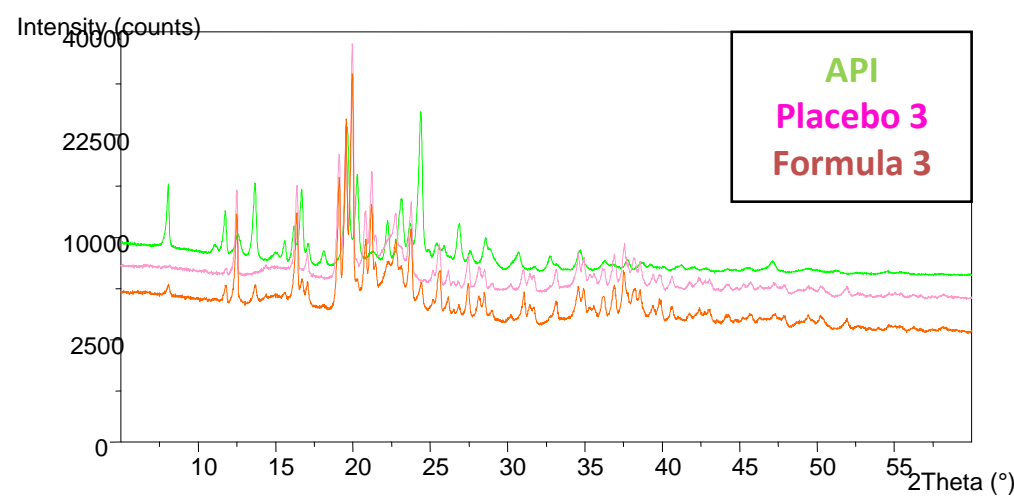

Figure 18: X-ray diffractometry comparison between API, placebo 3 and formula 3

\section{DISCUSSION}

\section{Thermal Analysis}

The analysis of the matrix or the corresponding placebo for each formula is based on the principle that states that thermal properties of mixtures will be quite approximate to the sum of the thermal properties of each component individually, assuming that there are no interactions between the excipients and the API. ${ }^{16}$

According to the results of the API's DSC analysis, it is possible to determine if it interacts chemically with the excipients that are present in the preformulation mixtures, based on the peaks that are shown in the thermograms, but most important related with the changes that may occur to the melting point of the substance. For the formulas of interest, the existence of an incompatibility was considered when the thermograms show a disappearance or widening of the API's fusion endotherm. ${ }^{5}$

In the DSC analysis, it is possible to notice that the samples corresponding to the prototype 3 , placebo and formula, differ from the mixtures of the other two prototypes, because they present an endothermic event around $57{ }^{\circ} \mathrm{C}$ and $59{ }^{\circ} \mathrm{C}$, respectively. It is important to highlight the presence of stearic acid as a lubricating agent in prototype 3 . Indeed, the peaks at the mentioned temperatures can be explained due to this excipient. The melting point of the component varies depending on its composition and purity, so according to various studies it has been observed that the fusion can occur between $50-70{ }^{\circ} \mathrm{C}$. Figure 3 shows the calorimetric curve of stearic acid, which indicates that for the sample in question, the fusion according to the DSC analysis occurs at $58.15^{\circ} \mathrm{C} .{ }^{6,17}$

Pregelatinized starch is the other compound that is included only in this prototype. Its thermogram found in the literature shows an extensive endotherm between 60 ${ }^{\circ} \mathrm{C}$ and $140{ }^{\circ} \mathrm{C}$ due to water loss. It can be observe in the DSC analysis shown in figure 3 , an endotherm for the excipient that occurs between $43.23^{\circ} \mathrm{C}$ and $111.62{ }^{\circ} \mathrm{C} .{ }^{5}$,

With the exception of the previously exposed situation regarding stearic acid, it is possible to observe that all the analysis of placebos and formulas by DSC follow a common pattern, in which the different events that can be identified show similar values in terms of enthalpy. The analysis of the curves depicts an extensive endotherm below $100{ }^{\circ} \mathrm{C}$, characteristic of the loss of absorbed moisture. In addition, it can be observed around $145^{\circ} \mathrm{C}$ that there is an endothermic event, which is explained by the dehydration of monohydrate lactose, as it follows the same behavior shown by the excipient in figure 3 . This event has been widely reported in the literature at temperatures around $144.47{ }^{\circ} \mathrm{C}$. The manifestation of the event at that temperature and not at $100{ }^{\circ} \mathrm{C}$ can be justified by the fact that since the waters are incorporated intramolecularly, the energy required to break the existing bonds must be greater. ${ }^{5,19}$

For magnesium stearate, literature establishes a first endothermic peak that occurs between $84-97{ }^{\circ} \mathrm{C}$, corresponding to its dehydration. It can be seen in figure 3 that this first event occurs at $80.48{ }^{\circ} \mathrm{C}$. Also, a second endothermic event is presented at $115.83{ }^{\circ} \mathrm{C}$, which according to the literature, it occurs between $112-121^{\circ}$ $\mathrm{C}$ and is linked to the fusions of its constituent fatty acids. ${ }^{7}$

Regarding sodium croscarmellose, studies report an extensive endothermic peak from $56{ }^{\circ} \mathrm{C}$ to approximately $117^{\circ} \mathrm{C}$, as a result of water loss. Figure 3 shows how that behavior is reflected in the analysis performed, since the endotherm occurs from $52.53{ }^{\circ} \mathrm{C}$ to $123.82{ }^{\circ} \mathrm{C}$. For another excipient, microcrystalline cellulose, literature indicates the existence of an endotherm from $57.5^{\circ} \mathrm{C}$ to $124.7^{\circ} \mathrm{C}$, while the analysis revealed that it occurs between $43.23{ }^{\circ} \mathrm{C}$ to $108.69^{\circ} \mathrm{C}$. In the case of povidone its melting point varies according the complexity of the polymer, showing in this case an endotherm that begins at $58.0{ }^{\circ} \mathrm{C}$ and its endpoint occurs at $114.31^{\circ} \mathrm{C} .^{7,20,21}$

Nevertheless, in spite of what literature establishes and the results presented in figure 3; the following excipients did not show significant thermal events in the analysis of placebos or formulas within the temperature range used: Pregelatinized starch, sodium croscarmellose, microcrystalline cellulose, magnesium stearate and povidone. The identification of the thermal events corresponding to each raw material is difficult to differentiate in these samples, because the components are present at least ten times lower compared to its individual analysis, with the only exception of microcrystalline cellulose which is present around $30 \%$ 
in the three prototypes. In addition, such a fact can also be explained due to the overlap with the rest of events occurring along to the temperature range worked, where the thermogram is governed mainly by the thermal behavior of the lactose monohydrate, since it is the diluent and therefore, the excipient present in a greater proportion. $\mathbf{5 , 1 8}$

On the other hand, literature indicates that the melting point of the fumarate salt present in the formulas is around $197-201{ }^{\circ} \mathrm{C}$ and according to the analysis presented in figure 2 , the active pharmaceutical principle has a melting peak at $201.38^{\circ} \mathrm{C}$. It can be observed in the calorimetric curves of figures $4-6$ relative to the formulas, that the melting point decreases around 197.16 ${ }^{\circ} \mathrm{C}$ for formula $1,195.94{ }^{\circ} \mathrm{C}$ for formula 2 and 195.48 ${ }^{\circ} \mathrm{C}$ for the third formula. It is important to emphasize that the API melts with decomposition, which implies that the temperature necessary to occur the decomposition of the drug is very close to its melting point. In all three cases there is evidence of decomposition, at approximately $201{ }^{\circ} \mathrm{C}$, although this event is practically overlapped with the endotherm corresponding to the start of the fusion of lactose. ${ }^{10,19}$

The analysis carried out by TGA allowed the measurement of the thermal stability of raw materials, the determination of the moisture content and / or solvents, and together with the DSC, it backs up the results obtained by each other. The method allows illustrating the thermal transitions of a material, where a mass loss occurs with each thermal event, which implies the volatilization of one or more components. With this technique it is only possible to detect chemical reactions, since physical changes such as fusion, do not imply a mass loss. ${ }^{22}$
According to the temperature division previously established in the results section, it can be said regarding to the TGA of the API (see figure 7), the lack of mass loss in the first stage of the thermogram can be interpreted as no loss of surface water, neither as decomposition events in that temperature range. It can also be explained by the lack of hydrates associated to the crystal. The behavior of the sample at this stage confirms what is shown by the thermogram of figure 2 . However, the second stage showed $20 \%$ of mass decrease between $205-208{ }^{\circ} \mathrm{C}$, which matches with a first decomposition event of the API and it is also in agreement with the decomposition temperature obtained by the differential scanning calorimetry analysis of the sample. Then, around $300{ }^{\circ} \mathrm{C}$ it is possible to appreciate a second and greater decomposition which is the responsible of the $75 \%$ loss of the mass sample. ${ }^{8,10,11}$

The thermogravimetric analysis carried out on the placebos and the formulas showed in the first stage, approximately before $140{ }^{\circ} \mathrm{C}$ a mass loss that does not exceed $5 \%$ of the sample. This confirms the dehydration of the monohydrated lactose, as well as the evaporation

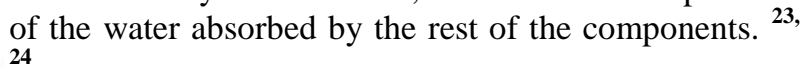

It is important to emphasize that literature reports three characteristic mass losses for lactose. Figure 19 exemplifies the three events in question, where the first decrease in mass of the sample occurs between $40{ }^{\circ} \mathrm{C}$ and $130{ }^{\circ} \mathrm{C}$, corresponding to the loss of absorbed water. The second one occurs between $130-150{ }^{\circ} \mathrm{C}$, and is due to the loss of the water of crystallization. Finally, when reaching $300{ }^{\circ} \mathrm{C}$ there is a continuous mass loss due to its decomposition. ${ }^{21,23}$

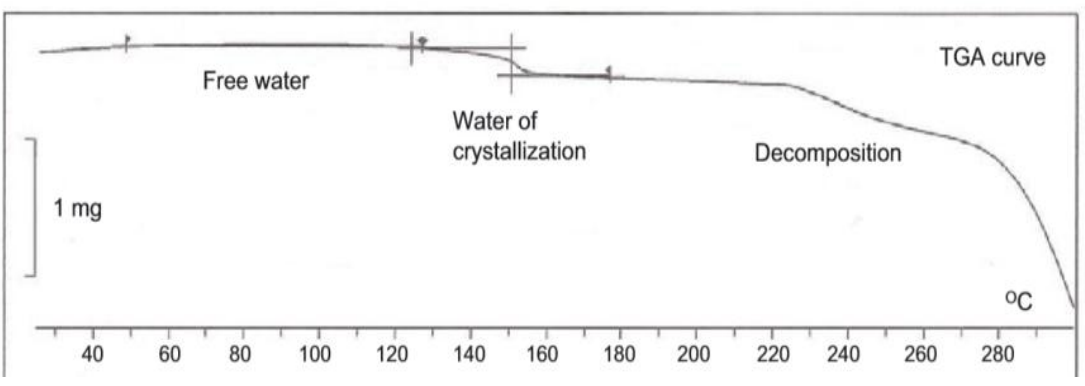

Figure 19: Thermogravimetric analysis of lactose monohydrate. (23)

Likewise, when comparing DSC and TGA thermograms corresponding to prototype 3 , it can be verified that indeed, the endotherm observed between 55 and $57{ }^{\circ} \mathrm{C}$ in the DSC, corresponds to the fusion of stearic acid, since the TGA doesn't show thermal events related to a mass loss that could indicate a decomposition event at that temperature.

Also, the mass loss at $200{ }^{\circ} \mathrm{C}$ in the TGA of the formulas reveals a decomposition of the API, which is in appearance according to the first decomposition event showed by the DSC analysis. Furthermore, for those samples the second mass loss between $280-300{ }^{\circ} \mathrm{C}$ is in agreement with the API's individual thermogravimetric analysis. Such loss of mass can be accompanied by other excipients decomposition such as sodium croscarmellose, magnesium stearate and povidone. After this event, all samples still have more than $79 \%$ of the initial mass. At higher temperatures the cellulose begins its decomposition process between $285-350{ }^{\circ} \mathrm{C}$, which also occurs along with a depolymerization processes. The sodium croscarmellose maintains a decomposition that can extend up to $600{ }^{\circ} \mathrm{C} .{ }^{\mathbf{2 4 , 2 5 , 2 6}}$

\section{Infrarred Spectroscopy}

For the purposes of the present investigation, IRS was used as it studies the absorption of energy by functional groups of the molecules that constitute the sample and is 
conceived as an extra method of corroboration of the compatibility results thrown by the DSC and TGA. ${ }^{27}$

It should be noted according to what is presented in figures $11-14$, that the bands identified for the API (see figure 11) can be found in powder formula mixtures (see figures 12 -14), so it is considered that there has not been any chemical change related to the drug.

\section{Ray Diffraction}

This non-destructive analytical technique provided detailed information about the internal arrangement of the crystalline substances in study. The analysis by XDR of the API did not reveal any differences in contrast to what is established in the literature, which indicates that the characteristic peaks for the polymorph $\mathrm{A}$ of the fumarate salt (only crystalline form reported) are: 11.6; $12.5 ; 13.6 ; 14.9 ; 15.5 ; 16.1 ; 16.6 ; 17.0 ; 18.1 ; 19.6 ; 20.2$; $21.3 ; 22.2 ; 23.1 ; 23.6 ; 24.3 ; 24.8 ; 25.4 ; 25.8 ; 26.8 ; 27.6$; $28.5 ; 28.8 ; 30.6 ; 32.7 ; 33.2 ; 34.6 ; 36.2 ; 36.8$ and 37.9 . The following diffractogram represents the peaks corresponding to the pattern, whose purity is $99.5 \%$.

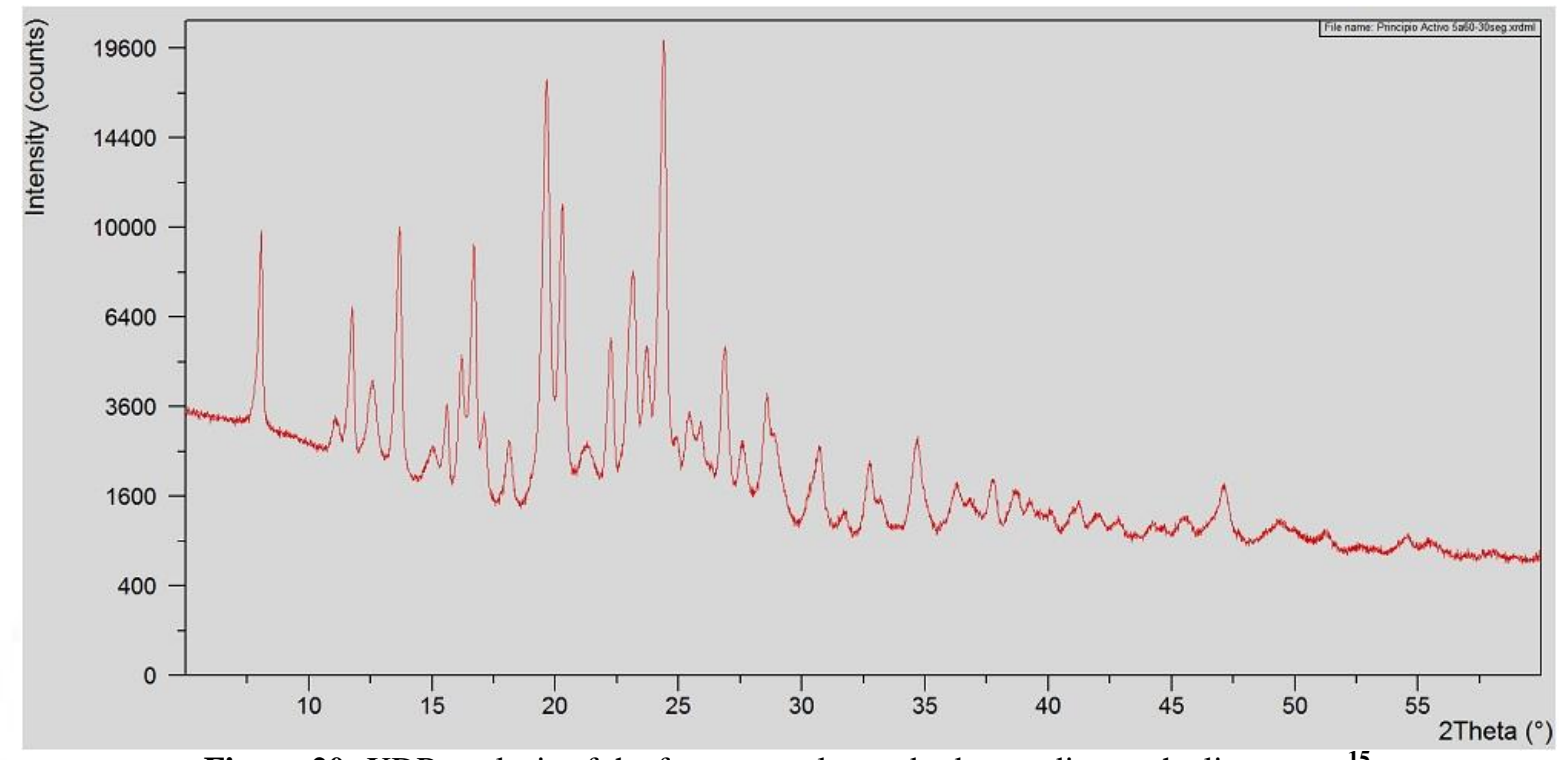

Figure 20: XDR analysis of the fumarate salt standard according to the literature. ${ }^{15}$

Similarly, the analysis corresponding to the powder formula did not reveal any alteration in the crystalline arrangement of the API, neither the excipients in question, as can be seen in figures 15 - 18. It's important to clarify that the intensity of the peaks corresponding to the drug, decreases in those analysis, since its concentration is much lower.

\section{CONCLUSIONS}

Although the thermal analysis results of the formulas show slight deviations in terms of melting temperature of the API, it is important to remember that DSC and TGA provide an approximate overview of the chemical and physical behavior of the formula, so they are methods used in a preliminary way to determine or rule out incompatibilities.

At the moment of carrying out analysis in the way previously described, it should be taken into consideration that multiple interactions may occur, which can cause a decrease in the melting temperature of the API. However, not all solid-solid interaction detected implies a chemical instability, that's because they can also be linked to the technological process used in manufacturing or to the proportion to which the API is present within the formulas. Therefore, the findings should be confirmed with another tool or method such as FTIR or HPLC, which will allow to definitively identify whether or not chemical incompatibility exists.

Following the results of the thermal analysis, it is preliminarily considered that the three formulas proposed are potential candidates for the development of a pharmaceutical product, since no significant chemical incompatibilities were detected between the API and the excipients. This situation is strongly supported by the results obtained through the XDR analysis and mainly by IRS, where no changes were detected for the molecule of the API.

However, based on the small changes in the melting point of the active pharmaceutical ingredient in the formulas, as well as in the composition of these, it is important to emphasize the extensive history of incompatibilities caused by magnesium stearate and stearic acid. In spite of the above and in case of confirmation of such fact, it is necessary to establish a criterion to determine if the incompatibility is really significant and implies a true risk for the quality, safety and efficacy of the medication. 


\section{REFERENCES}

1. Cardinal L. Technological Innovation in the Pharmaceutical Industry: The Use of Organizational Control in Managing Research and Development. Organization Science. 2001; 12(1):19-36.

2. Orfe, Y. (2014). Estudio de compatibilidad G0/excipientes mediante métodos isotérmicos y no isotérmicos. Santa Clara: Universidad Central "Marta Abreu" de las Villas.

3. Gibson M. Pharmaceutical preformulation and formulation. 2a ed. New York: Informa healthcare; 2009.

4. Cabeza Zabala, L. Y., \& Rojas Camargo, A. P. (2014). Estudio Comparativo de Tecnología DSC e Infrarrojo en la Identificación de Posibles Incompatibilidades en Mezclas Binarias Activo-Excipiente. Bogotá: Universidad de Ciencia y Tecnología.

5. Brown M, Antunes E, Glass B. DSC Screening of Potencial Prochlorperazine-excipiente Interactions in Preformulation Studies. Journal of Thermal Analysis and Calorimetry. 1999; 56:1317-1322.

6. Venkataram S, Khohlokwane M, Wallis S. Differential Scanning Calorimetry as a Quick Scanning Technique for Solid State Stability Studies. Drug Development and Industrial Pharmacy. 1995; 21(7):847-855.

7. Duarte F, Soares C, Accioly T, Nervo F. Compatibility study between chlorpropamide and excipients in their physical mixtures. Journal of Thermal Analysis and Calorimetry. 2009; 97(1):355-357.

8. Santamarta R. Caracterización de aleaciones base Ni-Ti producidas por solidificación rápida (melt-spinning), Palma: Universitat de les illesbalears, 2001.

9. Mazurek E, Winnicka K, Czajkowska A. Application of Diferential Scanning Calorimetry in Evaluation of Solid State Interactions in Tablets Containing Acetaminophen. Acta Poloniae Pharmaceutica. 2013; 70(5):787-793.

10. Uriach, J. \& Compañía S.A. 8-cloro-11-(1-((5-metil-3piridil) metil)-4-piperidiliden)6,11-dihidro-5H-benzo(5,6)cicloheptal(1,2-b)piridina, fumarato. España; ES 2087 818, 2017.

11. Zhuhai Jin Hong Pharmaceutical. One kind of fumaric rupatadine compounds, their synthesis and pharmaceutical compositions thereof. China; CN103804357 B, 2016.

12. AusPAR Rupafin Rupatadine iNova Pharmaceuticals (Australia) Pty Ltd PM-2009-03232-3-5.

13. Billah, M., Egan, R., Ganguly, A., Green, M. Discovery and Preliminary Pharmacology of Sch 37370, a Dual Antagonis of PAF and Histamine. In: Baumann W, ed. by. PlateletActivating Factor and Structurally Related Alkyl Ether
Lipids. 12th ed. New Jersey: AOCS Press; 1991. p. 11721174.

14. Castillo L, Madrigal G, Vargas R, Carazo G. Identification of Rupatadine fumarate polymorphic crystalline forms in pharmaceutical raw materials. Asian Journal of Science and Technology. 2018; 1(2):7482-7487.

15. Bio-Pharmaceutical. Rupatadine Fumarate A crystal form and preparation method thereof. China; CN106188008 A, 2016.

16. Pyramides $\mathrm{G}$, Robinson $\mathrm{J}$, Zito $\mathrm{W}$. The combined use of DSC and TGA for the thermal analysis of atenolol tablets. Journal of Pharmaceutical \& Biomedical Analysis. 1995; 13(2):103110 .

17. Djefel D, Makhlouf S. Experimental study of the thermal properties of composite stearic acid / coffee grounds / graphite for thermal energy storage. ACMA. 2014; 1-8.

18. Zeleznak K, Hoseney R. The Glass Transition in Starch. Cereal Chem. 1986; 64(2):121-124.

19. Brittain H, Blaine R. $\alpha$-Monohydrate Phase in Lactose by DSC. TA. 2014;:1-3.

20. Dvrn B, Bhavani N, Haarika B. Formulation Development and in Vitro Evaluation of Orally Disintegrating Tablets Containing Rizatriptan Benzoate. Research Journal of Pharmaceutical, Biological and Chemical Sciences. 2015; 6(1):300-311.

21. Fitzpatrick S, McCabe J, Petts C, Booth S. Effect of moisture on polyvinylpyrrolidone in accelerated stability testing. International Journal of Pharmaceutics. 2002; 246:143-151.

22. Haines P. Thermal Methods of Analysis. Dordrecht: Springer Netherlands; 1995.

23. Listiohadi Y, Hourigan J, Sleigh R, Steele R. Thermal analysis of amorphous lactose and $\alpha$-lactose monohydrate. Dairy Science and Technology. 2008; 89(1):43-67.

24. Ren S, Sun X, Lei T, Wu Q. The Effect of Chemical and High-Pressure Homogenization Treatment Conditions on the Morphology of Cellulose Nanoparticles. Journal of Nanomaterials. 2014; 2014:1-11.

25. Souza S, Araújo E, Morais F. Determination of calcium in tablets containing calcium citrate using thermogravimetry (TG). Braz J Therm Anal. 2013; 2(1):17-22.

26. SmithKline Beecham Corporation. High Druf Load Inmediate and Modified Release Oral Dosage Formulations and Processes for their Manufacture. USA; US 6,558,699 B2, 2003.

27. Chavakula R, Narayana M, Vijaya M. Spectral characterization of rupatadine fumarate and its potential impurities. OCAIJ. 2013; 9(4):143-147. 